\title{
Measurements of the effects of pure and salt water absorption on the rate-dependent response of an epoxy matrix
}

\author{
Gustavo Quino ${ }^{1}$, Antonio Pellegrino ${ }^{1}$, Vito L. Tagarielli ${ }^{2,1, *}$, Nik Petrinic $^{1}$ \\ ${ }^{1}$ Department of Engineering Science, University of Oxford, OX1 3PJ Oxford, UK \\ ${ }^{2}$ Department of Aeronautics, Imperial College, London, SW5 2AZ London, UK
}

\begin{abstract}
The study reports the measured effects of water absorption on epoxy resin. Epoxy samples were exposed to wet conditioning environments including pure water, $\mathrm{NaCl}$-water solution, and pure water at boiling temperature, measuring absorption as a function of time. Vickers hardness and indentation creep tests were performed and the mechanical response of the material to uniaxial stress was also measured in both compression and tension, at imposed strain rates in the range $0.001-2500 \mathrm{~s}^{-1}$. It was found that the absorption of both pure and salt water caused decrease of stiffness, yield stress and hardness, but only mildly affected the sensitivity of the response to the imposed strain rate and the tensile ductility. Mechanical testing after re-drying of the samples revealed the permanent effects of water absorption.
\end{abstract}

Keywords: epoxy, strain rate sensitivity, diffusion, water absorption, salt water.

Submitted to Composites Part B: Engineering, December 2017

\footnotetext{
*Corresponding author. Email: v.tagarielli@imperial.ac.uk
} 


\section{INTRODUCTION}

Marine applications of polymer composites are very wide, ranging from offshore and underwater structures for the oil industry to ships and submarines; this is due to the many advantages composites offer, such as their low density, corrosion resistance, and multifunctionality. One of the key challenges for fibre-reinforced polymers (FRPs) for marine applications is aging caused by seawater absorption, which can degrade their mechanical properties. Some research (for example, [1-5]) has been conducted on FRPs to understand and quantify this phenomenon and its effects on the mechanical performance of composites.

To allow effective designs and detailed numerical simulations of the effects of water absorption on the response of FRPs, it is necessary to measure the sensitivity of the constituents to water absorption. In this study we focus on a neat epoxy resin, due to its widespread application as a matrix material in FRPs. Several studies have been published on the effects of water absorption on different polymers (e.g. [6-9]), but to the best of our knowledge little research has been published, to date, on the effect of water exposure on the strain rate sensitivity [10-12] of the resin. This study aims at filling this gap in the literature, while providing a comprehensive dataset to guide FRP material design and to calibrate constitutive models used in numerical simulations.

The strain rate dependency of epoxy resins has been studied mostly experimentally (e.g. [1317]) and is widely accepted that high imposed strain rates tend to increase the yield stress $[13,14,17,18]$, the material stiffness $[16,18]$ and the compressive strength [16]; the ductility in tension and shear can in some cases be decreased [19], resulting in decreasing toughness [20].

Several studies have focused on the physical and chemical mechanisms governing water absorption in polymers. Apicella et al. [7] showed that absorbed water can dissolve the bulk polymer, make bonds with hydrophilic sites or occupy the material free volume. It is also accepted that chemical interaction (e.g. formation of both type-I and type-II bonds) plays a major role in the degradation of the mechanical response [21-23]. Zhou and Lucas [22] stress that such bonds may increase the overall molecules mobility, such that water acts as a plasticizer (Type I bonds) or induce secondary crosslinking (Type II bonds), which has the opposite effect to Type I bonds; which effect is prevalent depends on the details of the molecular structure, in ways that are difficult to predict in absence of detailed measurements. Xiao et al. [24] and De'Nève and Shanahan [21] also reported chain scission induced by water absorption. In some cases water molecules may remain free, causing only minor distortion of the microstructure 
[25]. Several authors studied the mechanisms of diffusion of water in different polymers; for some, diffusion has been observed to be in accordance to Fick's law [23,26], while for others such law was not adequate [27],[28]. Water absorption can modify several properties of polymers, such as glass transition temperature $\left(T_{g}\right)$ [22], stiffness [29,30], tensile strength $[29,31]$ and fracture toughness $[8,32]$. It also induces notable hygroscopic strains $[9,23,33,34]$. Several authors examined the reversibility of the effects of water absorption; in some cases these were fully reversible [22], while other authors observed permanent changes [24,30]. Zhou and Lucas [22] suggested that the change of $T_{g}$ is not only a function of the amount of absorbed water, but also of the time and temperature of exposure, as the amount of type-II bonds may be affected by temperature and time.

The published literature clearly shows that the mechanisms of water absorption and its effects on the mechanical response are complex and very difficult to model at molecular level; rather, extensive measurements are needed in order to quantify the effects of water absorption on the mechanical response of polymers. In this work we report, for an epoxy resin exposed to water, the diffusion properties, the Vickers micro-hardness, and the uniaxial tensile and compressive response for a wide range of imposed strain rates. We perform our measurement following exposure to pure water or a solution of $\mathrm{NaCl}$, at two different temperatures; we explore the effects of re-drying sample, to assess the reversibility of the microstructural changes induced by water absorption.

In the next Section we describe details on the material investigated and experimental methods used. In Section 3 we present the results, which are discussed in Section 4.

\section{EXPERimental Methods}

\subsection{Material and sample fabrication}

All samples were machined from $20 \mathrm{~mm}$ thick moulded plates of PRIME 20ULV, an ultralow viscosity resin system provided by Gurit, consisting of a mix of Prime 20LV resin and a slow epoxy hardener. The choice of this material is dictated by the fact that this resin, or resins of similar formulations, find widespread application in the manufacturing, via resin transfer moulding, of GFRPs plates, which are very popular in marine construction. Epoxy plates were made by slowly pouring de-gassed resin between glass plates; the system was cured at room temperature for 24 hours and post-cured at $50^{\circ} \mathrm{C}$ for 16 hours, prior to slow cooling (over 24 hours) to room temperature. Abundant coolant was used during machining to avoid overheating. 
The volume of tension and compression specimens was minimised, to reduce the time necessary to achieve water saturation. For compression tests, circular cylindrical specimens of diameters of 4 and $6 \mathrm{~mm}$ were fabricated (denoted as D4 and D6, respectively), with dimension as in Figure 1 and Table 1 . The ratio of height $H$ to diameter $d$ was set to $\sqrt{3} / 4$, following the recommendation of Gorham [35] for testing at high strain rate. This low aspect ratio may result in a considerable hydrostatic stress component during test, which was prevented using petroleum jelly as lubricant.

Table 1. Geometry of 2 sample sizes of compression specimens

\begin{tabular}{|c|c|c|}
\hline ID & $\begin{array}{c}d \\
(\mathrm{~mm})\end{array}$ & $\begin{array}{c}H \\
(\mathrm{~mm})\end{array}$ \\
\hline D6 & 6 & 2.60 \\
\hline D4 & 4 & 1.73 \\
\hline
\end{tabular}

Dogbone-shaped, round tensile specimens (denoted $\mathrm{T}$ in the figures) were machined with threaded ends for easy mounting in the testing apparatus (the specimen dimension are summarised in the drawing in Figure 2).

\subsection{Water absorption}

Underwater structures can be continuously submerged for periods of up to a couple of decades, but obviously an experimental campaign with the same time span is not practical. For this reason, accelerated absorption was performed by immersing the samples in pure distilled water (PW) at $50^{\circ} \mathrm{C}$, which is below the $T_{g}$ of this epoxy $\left(81^{\circ} \mathrm{C}\right.$ according to the manufacturer) and can be reached in some extreme applications. For the case of immersion in salt water, $\mathrm{NaCl}$ solutions (SW) were prepared by dissolving $\mathrm{NaCl}$ in distilled water at $50^{\circ} \mathrm{C}(18 \mathrm{~g}$ of salt per $100 \mathrm{ml}$ of water). A smaller group of compression specimens was immersed in boiling water (BW), to explore the consequences of water absorption at temperature above $T_{g}$. For these tests, water was kept slightly below the point of incipient boiling (at approximately $99^{\circ} \mathrm{C}$ ), to avoid possible effects of the exposure of specimens to water vapour.

Before water immersion, samples were dried for up to 500 hours in a Binder® FED series oven, at $50^{\circ} \mathrm{C}$. A small batch of samples, labelled in the following as "as manufactured" (AM), was not dried, to assess the effects of the initial drying on the material properties. During drying, 
the mass was monitored regularly, weighing the specimens with a precision balance (OHAUS DV215, $0.01 \mathrm{mg}$ resolution), thereby determining the water content defined as $\% \Delta w_{t}$.

$$
\% \Delta w_{t}=\frac{w_{t}-w_{d r y}}{w_{d r y}} \times 100 \%
$$

where $w_{t}$ is the weight at the time $t$ and $w_{d r y}$ is the final weight of the fully dry specimens $\left(\% \Delta w_{t}=0\right)$. The compression specimens reached a steady weight after approximately 250 hours, while tensile specimens were fully dry after approximately 450 hours.

Following drying, a set of samples were placed in the PW bath, reaching saturation after 1000 hours. A second group of dry samples was immersed in the SW bath, reaching a steady state after 600-1000 hours of immersion. To achieve a uniform diffusion, all faces of the specimens were in contact with water; this was ensured by placing the samples on a fine metallic mesh, avoiding contact with the walls of the container. A third set of dry D4 samples was placed in a container with boiling water (BW) for up to 8 hours, which guaranteed saturation.

The absorption of water was monitored by weighing the samples, thereby determining the percent water content $\% \Delta w_{t}$, defined as in eq. (1). At saturation the maximum weight was reached, corresponding to a water content of $\% \Delta w_{s}$. The measured time histories of water absorption are reported in Fig. 4.

To track the degradation of properties, some of the samples were extracted from the water bath at different times and tested at different imposed strain rates $\left(0.001-2500 \mathrm{~s}^{-1}\right)$; at least three specimens were tested in each condition, to quantify scatter. Average and the standard deviation of the measurements will be reported in the following.

To study the recoverability of the mechanical properties after saturation, selected saturated samples were re-dried in the oven at $50^{\circ} \mathrm{C}$ until no significant weight change was observed, and subsequently tested. These groups will be identified as PW-RD and SW-RD, for re-drying after pure and salt water saturation respectively.

\subsection{Diffusion response}

To characterise the diffusion of pure water in the epoxy resin, flat plates of epoxy measuring $30 \times 50 \times 2.4 \mathrm{~mm}^{3}$ were manufactured and subjected to an initial drying cycle, followed by a water immersion cycle, as described above. The change of mass in the plate as a function of time of immersion was used to back-calculate the diffusion parameters, as follows. 
Preliminary compression tests in 3 different directions revealed that the mechanical response of the epoxy was approximately isotropic, suggesting an isotropic microstructure. The first and second Fick's laws of diffusion, in their isotropic form, read, respectively, as

$$
\begin{aligned}
& \underline{J}=-D \nabla \phi \\
& \frac{\partial \phi}{\partial t}=D \nabla^{2} \phi
\end{aligned}
$$

where $J$, is the diffusion flux vector, $\phi$ is the concentration in arbitrary units, $D$ is the diffusivity of the material, and $t$ is time. For the case of one-dimensional diffusion in a thin plate of thickness $h$, integration of Eqns (2) and (3) gives

$$
\frac{M_{t}}{M_{s}}=1-\frac{8}{\pi^{2}} \sum_{n=0}^{\infty} \frac{1}{(2 n+1)^{2}} \exp \left[-\frac{(2 n-1)^{2} D t \pi^{2}}{h^{2}}\right]
$$

where $M_{t}$ is the mass of solute at time $t, M_{s}$ is the mass of solute at saturation. Equation (4) can be approximated numerically by Eq. (5) [36]

$$
\frac{M_{t}}{M_{s}}=\left(1-\exp \left(-7.3\left(\frac{D t}{h^{2}}\right)^{0.75}\right)\right)
$$

Equation (5) shows that, in the hypothesis that Fick's laws hold, the diffusion is characterised by two parameters, the diffusivity $D$ and the water content at saturation, $M_{s}$. The fidelity of this equation, strictly valid only for an infinite plate, was assessed by Finite Element simulations performed in Comsol [37] on the geometry of our finite plates. The constitutive response was assumed to obey Fick's law; the outer boundaries were assumed to be fully saturated at time $t=0$ and the time history of the water content at every point was predicted until full saturation. Fitting Eq. (5) to the measured water content of the epoxy plate (PL), as shown in Fig. 5, allowed determining the diffusion parameters. Figure 5 includes FE predictions of the time history of average water content in the sample, showing the accuracy of eq. (5).

The good accuracy of the FE predictions suggested that water diffusion followed Fick's laws in the case of pure water (PW). The diffusion parameters in the case of salty water and boiling pure water (SW and BW, respectively) were determined from the measured absorption histories on small cylindrical specimens of type D4, as using these small specimens allowed saving material and time. An iterative procedure was used to obtain fittings of FE predictions (obtained to simulate water absorption of D4 specimens) to the measurements, shown in Fig. 5. The 
procedure consisted in running FE simulations with several values of diffusivity (varied in steps of $0.01 \times 10^{-13} \mathrm{~m}^{2} / \mathrm{s}$ for SW and $0.01 \times 10^{-11} \mathrm{~m}^{2} / \mathrm{s}$ for BW) and the measured value of water content. This allowed identifying the optimal values of diffusivity to minimise the differences between experiments and predictions.

As evident from Fig. 5, diffusion was found to follow Fick's laws also for the cases of SW and

$\mathrm{BW}$. The diffusivities for PW, SW and BW were $D_{P W}=6.05 \times 10^{-13} \mathrm{~m}^{2} / \mathrm{s}, D_{S W}=5.6 \times$ $10^{-13} \mathrm{~m}^{2} / \mathrm{s}$ and $D_{B W}=2.7 \times 10^{-11} \mathrm{~m}^{2} / \mathrm{s}$. The water contents at saturation were of approximately $2.7 \%, 2 \%$ and $2.9 \%$ for PW, SW and BW, respectively.

Figure 6 presents the loss of water of different specimens upon re-drying. Figure 6a suggests that, for the case of PW, approximately $0.3 \%$ of water remains in the polymer after full redrying; for the case of SW the fraction of water mass permanently trapped in the polymer's structure is of order $0.1 \%$.

\subsection{Mechanical characterisation}

Mechanical tests were conducted in a laboratory at $40 \pm 8 \%$ relative humidity and $21 \pm 2^{\circ} \mathrm{C}$. Samples were taken out of the water bath and tested within $30 \mathrm{~min}$ as recommended by ASTM D618 [38], in order to avoid significant water loss in the sample due to evaporation.

Quasi-static tests were performed using a screw-driven testing machine (Zwick Z250) with a $20 \mathrm{kN}$ resistive load cell; nominal strain rates of either $0.001 \mathrm{~s}^{-1}$ or $0.1 \mathrm{~s}^{-1}$ were imposed onto the gauge portions of the samples. In compression the epoxy cylinders were forced to deform by two lubricated metallic platens, while in tension metallic threaded grips were used; in both cases stretching of the samples was measured by a laser extensometer (make E.I.R. Model LE05) of resolution $1 \mu \mathrm{m}$.

Uniaxial compression and tension tests at strain rates equal to or greater than $200 s^{-1}$ were performed in split Hopkinson bars with setups as described in $[17,39,40]$. In compression, onedimensional wave theory was used to deduce the histories of stress and strain on the specimens, as described in Harding and Welsh [41]. In tension, the stress versus time history was deduced by wave theory while the history of strain was obtained by analysing high speed video footage recorded at 200000 fps (by a Specialised Imaging Kirana camera). Force equilibrium was reached after approximately $40 \mu \mathrm{s}$ in compression and $100 \mu \mathrm{s}$ in tension, corresponding to axial strains of approximately 0.01 and 0.02 , respectively. The strain rate imposed onto the gauge portion of the samples was approximately constant following dynamic equilibrium. 
Microhardness tests were performed using a hardness meter (Wilson TUKON 1202) with a Vickers indenter. The machine operates by releasing a weight of $0.5 \mathrm{~kg}$ onto the Vickers indenter, and removing the load after a prescribed dwell time; this was set to either 10,50 or $100 \mathrm{~s}$, to deduce the indentation creep response of the epoxy tested.

\section{RESULTS}

Results are reported, in the following, indicating by a letter whether they refer to tensile (T) or compression $(\mathrm{C})$ test; the letter is followed by an indication of the conditioning of the specimen. In some cases, the last number indicates the strain rate in the test.

Figure 7 shows representative true strain-stress curves in compression and tension, at strain rate $0.001 \mathrm{~s}^{-1}$. After an initial elastic regime, the curves show a local maximum in flow stress, denoted as yield stress (YS) in the following. In compression, this is followed by softening and subsequent strain hardening. In tension the response was similar, but ductile failure intervened in some cases prior to strain-hardening. The compressive response was stronger than the tensile response, as expected, and the tensile ductility does not decrease (and, in some cases, increases) as a consequence of water absorption.

Figure 8 displays representative true strain-stress curves in tension and compression; the average strain rate following force equilibrium is denoted, in $\mathrm{s}^{-1}$, by the number in the labels. In the following we shall denote as yield stress (YS) either the first peak in flow stress (where this is present) or, where strain-softening is not observed (i.e. when the response does not display a stress peak), as the flow stress at a true strain $\varepsilon_{D r y}^{Y S}$; the strain $\varepsilon_{D r y}^{Y S}$ denotes the strain at peak stress for the corresponding quasi-static test. In compression, the strain-softening phase was negligible, compared to the quasi-static measurements in Fig. 7; the strain-hardening phase was much more pronounced in dynamic tests than in quasi-static tests. Similar observations apply to the measured tensile response in dynamic tests; the specimen's ductility was much lower in dynamic measurements then in quasi-static tests, as expected.

Figures 9 and 10 summarise the measured yield stress (YS) and apparent modulus (E) at $0.001 \mathrm{~s}^{-1}$ for different types of specimens and following different conditioning procedures. Figures 11 and 12 present similar information for tests conducted at a strain rate of $0.1 \mathrm{~s}^{-1}$.

To highlight the progressive change in mechanical response with increasing water intake, compressive strength and stiffness (measured at strain rates of $0.001 \mathrm{~s}^{-1}$ and $0.1 \mathrm{~s}^{-1}$ ) are shown 
in Figure 13 as a function of water intake. Figures 14 and 15 illustrate the strain rate sensitivity in compression and tension, respectively, and after different conditioning procedures.

The results of Vickers hardness measurements are shown in Figure 16. The effects of drying, saturation in PW and SW and re-drying are shown, for 3 different load dwelling times. While this is not pursued here for the sake of brevity, the data in Fig. 16 can be used to extract the visco-plastic properties of the material in the quasi-static regime, by fitting to appropriate models for the creep indentation of visco-plastic solids (e.g. [42]).

\section{DISCUSSION}

\subsection{Water diffusion in epoxy resin}

The measured values of diffusivity are in line with previous findings by Scott and Lees [43]. The smaller diffusivity in salt water has been previously explained by a mechanism of inverse osmosis [44], which also justifies the smaller water content at saturation and the differences in residual water content after re-drying.

In boiling water the diffusivity is two orders of magnitude higher than in pure or salt water at $50^{\circ} \mathrm{C}$. Previous studies $[26,45]$ have shown that the water content at saturation in pure water is approximately independent of temperature, at temperatures below $T_{g}$; in this study we found that in boiling water the saturation water content is slightly higher than in pure water; it can be conjectured that since $T_{g}$ is below the boiling point of water free volumes increase [23], allowing for additional water molecules to reach the bulk of the material.

\subsection{Effects of initial drying}

These effects are evaluated by comparing results of AM specimens with the dry ones in Figures 9-12. Drying increases mildly both YS and E in the quasi-static regime. This is confirmed by the hardness measurements shown in Figure 16 . We deduce that the small $(0.35 \%$ $0.5 \%$ ) water content initially present in the specimens is acting as a weakening agent of the material. For tests at high strain rate (Figs. 14 and 15), the mild improvement upon drying could not be detected, possibly due to the higher intrinsic scatter in the dynamic tests. 


\subsection{Effects of water absorption}

Water absorption clearly showed detrimental effects on the mechanical properties of the epoxy, at all strain rates (Figs. 13-15). The modulus, yield stress, and hardness reduced with increasing water content. Most of the stiffness and strength degradation observed in quasi-static tests occurred after the first 2 weeks of immersion (corresponding to approximate water intakes of $2.5 \%$ and $1.5 \%$ in PW and SW, respectively, Fig. 13). This indicates that a good estimate of the degradation of mechanical properties may be obtained (for the specimen volume investigated here) after only 2 weeks of immersion. FE simulations, not showed here for the sake of brevity, confirmed that after 2 weeks of immersion the concentration of water in the specimen is uniform in specimens of type D4, within a margin of approximately $5 \%$.

Figures 14 and 15 show that while strength reduced with water intake, its sensitivity to strain rate remained approximately unchanged.

\subsection{Effects of aging above $T_{g}$}

Figure 13 includes the measured properties of specimens aged in boiling water (BW) and shows that clearly this conditioning is the most detrimental, with the strength reducing by $40 \%$ compared to fully dry specimens. Immersion in boiling water was a very effective way to accelerate water uptake, however the effects on the properties are not equivalent to ageing at lower temperatures due to additional mechanisms occurring, such as the breaking of both primary and secondary bonds.

\subsection{Effects of salinity}

Figures 9-16 show that specimens conditioned by salt water have similar properties degradation as specimens conditioned by pure water, even though different values of water content are reached at saturation by these two different types of conditioning. This reinforces the notion that degradation of the mechanical response depends strongly on the composition of the solution diffused in the polymer and not only on the amount of solution absorbed.

\subsection{Effects of re-drying: recoverability of properties}

As seen in Figures 9-12 and 16, mechanical properties were recovered by up to $91 \%$ of the values in fully dry conditions. This is related to the data in Figure 6, showing that the drying 
process does not allow removing all water, consistent with the observations of Zhou and Lucas, who reported they were unable to remove all water in their samples even after 1450 hours of exposure at $60^{\circ} \mathrm{C}[26]$.

\subsection{Effects of strain rate}

Figure 13-15 show a clear strain rate sensitivity of this polymer, in line with previously reported data for dry polymers. The mechanical properties are reduced, for conditioned specimens, at all strain rates. The ratio of saturated to dry property however is not the same for the different strain rates. In tests at $0.001 \mathrm{~s}^{-1}$, for instance, water saturation induced more degradation on $\mathrm{E}$ (23-25\% decrease) than in experiments at $0.1 \mathrm{~s}^{-1}$ (8-16\% reduction). In general, the mechanical response of the epoxy at high strain rates is less affected by degradation, resulting in a slightly higher strain rate sensitivity for conditioned samples compared to dry samples.

\section{CONCLUDING REMARKS}

We presented the results of an experimental campaign exploring the effects of conditioning in pure, salt, or boiling water on the mechanical response of an epoxy commonly used in marine composite constructions, over a wide range of applied strain rates. We characterised the diffusion parameters for the three different types of conditioning, and diffusion was found to obey Fick's law. We suggested optimal sizes of specimens and conditioning procedures to conduct similar investigations on other materials. We presented a comprehensive set of measurements for the epoxy under investigation, which can be used to simulate the response of fibre-reinforced epoxy after different types of conditionings and at different strain rates; we leave this investigation as a subject for further research. The main conclusions from this study are as follows.

- The diffusion of pure, salt and boiling water in epoxy obeys Fick's law. The diffusivity of pure boiling water in Epoxy is two orders of magnitude greater than in pure water at $50{ }^{\circ} \mathrm{C}$.

- $\quad$ The water absorbed in specimens up to saturation cannot be fully removed by drying.

- Conditioning in salt water solutions until saturation has similar effects on the mechanical properties as conditioning in pure water; conditioning in boiling water has the most 
detrimental effects on mechanical response. The three different conditionings explored in this study correspond to different water contents at saturation.

- At all strain rates, conditioning until saturation results in a marked decrease in stiffness and strength. The relative decrease in stiffness is higher than the decrease in strength. Tensile ductility was not detrimentally affected by conditioning.

- After conditioning the material retains a similar strain rate sensitivity to that measured in fully dry conditions.

\section{ACKNOWLEDGEMENTS}

This project was supported by EPSRC, [dstl] and Rolls-Royce plc [grant EP/G042586/1]. We are grateful to S. Carter and J. Fullerton for assistance with specimen manufacturing. Dr Tagarielli acknowledges the Department of Aeronautics at Imperial and the Department of Engineering Science at Oxford for supporting his visiting position at Oxford. 


\section{REFERENCES}

[1] S. Aldajah, G. Alawsi, S.A. Rahmaan, Impact of sea and tap water exposure on the durability of GFRP laminates, Mater. Des. 30 (2009) 1835-1840. doi:10.1016/j.matdes.2008.07.044.

[2] A. Kootsookos, A.P. Mouritz, Seawater durability of glass- and carbon-polymer composites, Compos. Sci. Technol. 64 (2004) 1503-1511. doi:10.1016/j.compscitech.2003.10.019.

[3] G. Steinbrecher, B. Cohen, E. Altus, Hygromechanical coupling in laminate composites and its effect on interlaminar failure, Compos. Part A Appl. Sci. Manuf. 84 (2016) 123133. doi:10.1016/j.compositesa.2016.01.012.

[4] M. Assarar, D. Scida, A. El Mahi, C. Poilâne, R. Ayad, Influence of water ageing on mechanical properties and damage events of two reinforced composite materials: Flaxfibres and glass-fibres, Mater. Des. 32 (2011) 788-795.

[5] B. Dewimille, A.R. Bunsell, Accelerated ageing of a glass fibre-reinforced epoxy resin in water, Composites. 14 (1983) 35-40.

[6] S. Alessi, D. Conduruta, G. Pitarresi, C. Dispenza, G. Spadaro, Hydrothermal ageing of radiation cured epoxy resin-polyether sulfone blends as matrices for structural composites, Polym. Degrad. Stab. $95 \quad$ (2010) 677-683. doi:10.1016/j.polymdegradstab.2009.11.038.

[7] A. Apicella, R. Tessieri, C. de Cataldis, Sorption modes of water in glassy epoxies, J. Memb. Sci. 18 (1984) 211-225. doi:10.1016/S0376-7388(00)85035-8.

[8] G. Quino, J. El Yagoubi, G. Lubineau, Characterizing the toughness of an epoxy resin after wet aging using compact tension specimens with non-uniform moisture content, $\begin{array}{lllll}\text { Polym. } & \text { Degrad. } & \text { Stab. } & 109 & \text { (2014) }\end{array}$ doi:10.1016/j.polymdegradstab.2014.08.005.

[9] M. Lai, J. Botsis, J. Cugnoni, D. Coric, An experimental-numerical study of moisture absorption in an epoxy, Compos. Part A Appl. Sci. Manuf. 43 (2012) 1053-1060. doi:http://dx.doi.org/10.1016/j.compositesa.2012.01.027.

[10] Vuoristo, T., V.-T. Kuokkala, Effect of Strain Rate, Moisture and Temperature on the Deformation Behavior of Polymer Roll Covers, Exp. Mech. 44 (2004) 313-319. doi:10.1177/0014485104042949.

[11] E. Woldesenbet, N. Gupta, J.R. Vinson, Determination of moisture effects on impact properties of composite materials, J. Mater. Sci. 37 (2002) 2693-2698. doi:10.1023/A:1015864932198.

[12] E. Kontiou, G. Spathis, C. Kavadias, Viscoplastic Behaviour of PMMA Blends-the Effect of Moisture Absorption, J. Reinf. Plast. Compos. 16 (1997) 306-320. doi:10.1177/073168449701600402.

[13] T. Gómez-del Río, J. Rodríguez, Compression yielding of epoxy: Strain rate and temperature effect, Mater. Des. 35 (2012) 369-373. doi:10.1016/j.matdes.2011.09.034.

[14] T. Gómez-del Río, J. Rodríguez, R.A. Pearson, Compressive properties of nanoparticle modified epoxy resin at different strain rates, Compos. Part B Eng. 57 (2014) 173-179. doi:10.1016/j.compositesb.2013.10.002.

[15] T. Gómez-del Río, A. Salazar, J. Rodríguez, Effect of strain rate and temperature on tensile properties of ethylene--propylene block copolymers, Mater. Des. 42 (2012) 301307.

[16] M.F. Omar, H.M. Akil, Z.A. Ahmad, Measurement and prediction of compressive properties of polymers at high strain rate loading, Mater. Des. 32 (2011) 4207-4215.

[17] R. Gerlach, C.R. Siviour, N. Petrinic, J. Wiegand, Experimental characterisation and constitutive modelling of RTM-6 resin under impact loading, Polymer (Guildf). 49 (2008) 2728-2737. doi:10.1016/j.polymer.2008.04.018. 
[18] D. Mohotti, M. Ali, T. Ngo, J. Lu, P. Mendis, Strain rate dependent constitutive model for predicting the material behaviour of polyurea under high strain rate tensile loading, Mater. Des. 53 (2014) 830-837.

[19] A. Gilat, R.K. Goldberg, G.D. Roberts, Strain Rate Sensitivity of Epoxy Resin in Tensile and Shear Loading, J. Aerosp. Eng. 20 (2007) 75-89. doi:10.1061/(ASCE)08931321(2007)20:2(75).

[20] K. Hollmann, H.T. Hahn, Plane-strain fracture toughness of epoxies at different loading rates, Polym. Eng. Sci. 29 (1989) 523-530. doi:10.1002/pen.760290806.

[21] B. De'Nève, M. Shanahan, Water absorption by an epoxy resin and its effect on the mechanical properties and infra-red spectra, Polymer (Guildf). 34 (1993) 5099-5105.

[22] J. Zhou, J.P. Lucas, Hygrothermal effects of epoxy resin. Part II: variations of glass transition temperature, Polymer (Guildf). 40 (1999) 5513-5522. doi:10.1016/S00323861(98)00791-5.

[23] X.J. Fan, S.W.R. Lee, Q. Han, Experimental investigations and model study of moisture behaviors in polymeric materials, Microelectron. Reliab. 49 (2009) 861-871. doi:10.1016/j.microrel.2009.03.006.

[24] G.Z. Xiao, M. Delamar, M.E.R. Shanahan, Irreversible interactions between water and DGEBA/DDA epoxy resin during hygrothermal aging, J. Appl. Polym. Sci. 65 (1997) 449-458. doi:10.1002/(SICI)1097-4628(19970718)65:3<449::AID-APP4>3.0.CO;2H.

[25] C. Grave, I. McEwan, R.R.A. Pethrick, Influence of stoichiometric ratio on water absorption in epoxy resins, J. Appl. Polym. ... 69 (1998) 2369-2376. doi:10.1002/(SICI)1097-4628(19980919)69:12<2369::AID-APP8>3.0.CO;2-6.

[26] J. Zhou, J.P. Lucas, Hygrothermal effects of epoxy resin. Part I: the nature of water in epoxy, Polymer (Guildf). 40 (1999) 5505-5512. doi:10.1016/S0032-3861(98)00790-3.

[27] J. El Yagoubi, G. Lubineau, F. Roger, J. Verdu, A fully coupled diffusion--reaction scheme for moisture sorption--desorption in an anhydride-cured epoxy resin, Polymer (Guildf). 53 (2012) 5582-5595. doi:http://dx.doi.org/10.1016/j.polymer.2012.09.037.

[28] Y.C. Lin, X. Chen, Moisture sorption--desorption--resorption characteristics and its effect on the mechanical behavior of the epoxy system, Polymer (Guildf). 46 (2005) 11994-12003. doi:10.1016/j.polymer.2005.10.002.

[29] S. Sugiman, A.D. Crocombe, I.A. Aschroft, Experimental and numerical investigation of the static response of environmentally aged adhesively bonded joints, Int. J. Adhes. Adhes. 40 (2013) 224-237. doi:10.1016/j.ijadhadh.2012.08.007.

[30] A. Boubakri, K. Elleuch, N. Guermazi, H.F. Ayedi, Investigations on hygrothermal aging of thermoplastic polyurethane material, Mater. Des. 30 (2009) 3958-3965. doi:10.1016/j.matdes.2009.05.038.

[31] P.Y. Le Gac, D. Choqueuse, D. Melot, Description and modeling of polyurethane hydrolysis used as thermal insulation in oil offshore conditions, Polym. Test. 32 (2013) $1588-1593$.

[32] S. Alessi, D. Conduruta, G. Pitarresi, C. Dispenza, G. Spadaro, Accelerated ageing due to moisture absorption of thermally cured epoxy resin/polyethersulphone blends. Thermal, mechanical and morphological behaviour, Polym. Degrad. Stab. 96 (2011) 642-648. doi:http://dx.doi.org/10.1016/j.polymdegradstab.2010.12.027.

[33] E.L. McKague, J.D. Reynolds, J.E. Halkias, Swelling and glass transition relations for epoxy matrix material in humid environments, J. Appl. Polym. Sci. 22 (1978) 16431654. doi:10.1002/app.1978.070220615.

[34] J. El Yagoubi, G. Lubineau, S. Saghir, J. Verdu, A. Askari, Thermomechanical and hygroelastic properties of an epoxy system under humid and cold-warm cycling conditions, Polym. Degrad. Stab. 99 (2014) 146-155. doi:10.1016/j.polymdegradstab.2013.11.011. 
[35] D.A. Gorham, Specimen inertia in high strain-rate compression, J. Phys. D. Appl. Phys. 22 (1989) 1888-1893. doi:10.1088/0022-3727/22/12/014.

[36] C.-H. Shen, G.S. Springer, Moisture Absorption and Desorption of Composite Materials, J. Compos. Mater. 10 (1976) 2-20. doi:10.1177/002199837601000101.

[37] COMSOL AB, COMSOL Multiphysics v. 4.4. www.comsol.com, (2013).

[38] ASTM International, ASTM D618, 2008, Standard Practice for Conditioning Plastics for Testing, (2008). doi:10.1520/D0618-08.

[39] C.. Buckley, J. Harding, J.. Hou, C. Ruiz, A. Trojanowski, Deformation of thermosetting resins at impact rates of strain. Part I: Experimental study, J. Mech. Phys. Solids. 49 (2001) 1517-1538. doi:10.1016/S0022-5096(00)00085-5.

[40] A. Pellegrino, V.L. Tagarielli, R. Gerlach, N. Petrinic, The mechanical response of a syntactic polyurethane foam at low and high rates of strain, Int. J. Impact Eng. 75 (2015) 214-221. doi:10.1016/j.ijimpeng.2014.08.005.

[41] J. Harding, L.M. Welsh, A tensile testing technique for fibre-reinforced composites at impact rates of strain, J. Mater. Sci. 18 (1983) 1810-1826. doi:10.1007/BF00542078.

[42] S. Iliev, X. Chen, M.V. Pathan and V.L.Tagarielli, Measurements of the mechanical response of Indium and of its size dependence in bending and indentation, Mat. Sci. Eng. A. 683 (2017) 244-251.

[43] P. Scott, J.M. Lees, Water, salt water, and alkaline solution uptake in epoxy thin films, J. Appl. Polym. Sci. 130 (2013) 1898-1908. doi:10.1002/app.39331.

[44] R.C.L. Tai, Z. Szklarska-Smialowska, Effect of fillers on the degradation of automotive epoxy adhesives in aqueous solutions, J. Mater. Sci. 28 (1993) 6199-6204. doi:10.1007/BF00365044.

[45] I. Merdas, F. Thominette, J. Verdu, Humid aging of polyetherimide. I. Water sorption characteristics, J. Appl. Polym. Sci. 77 (2000) 1439-1444. doi:10.1002/10974628(20000815)77:7<1439::AID-APP5>3.0.CO;2-F. 


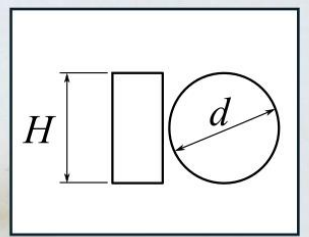

Figure 1. Compression specimens.

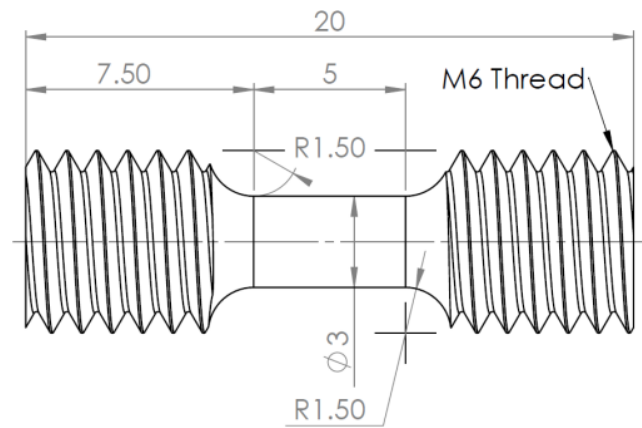

Figure 2. Tensile specimens.

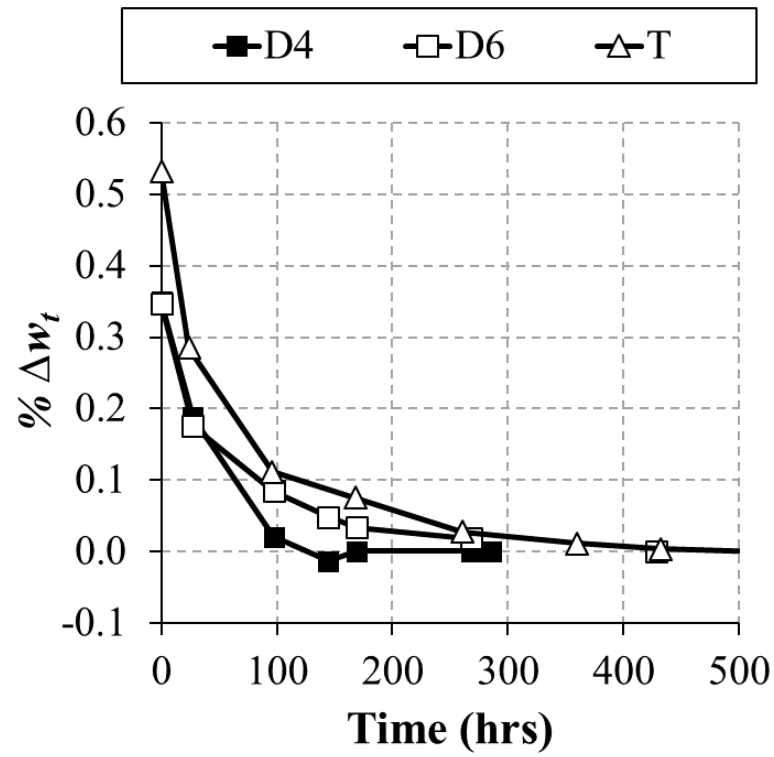

Figure 3. Water content of D4, D6, and T samples during the drying process. 


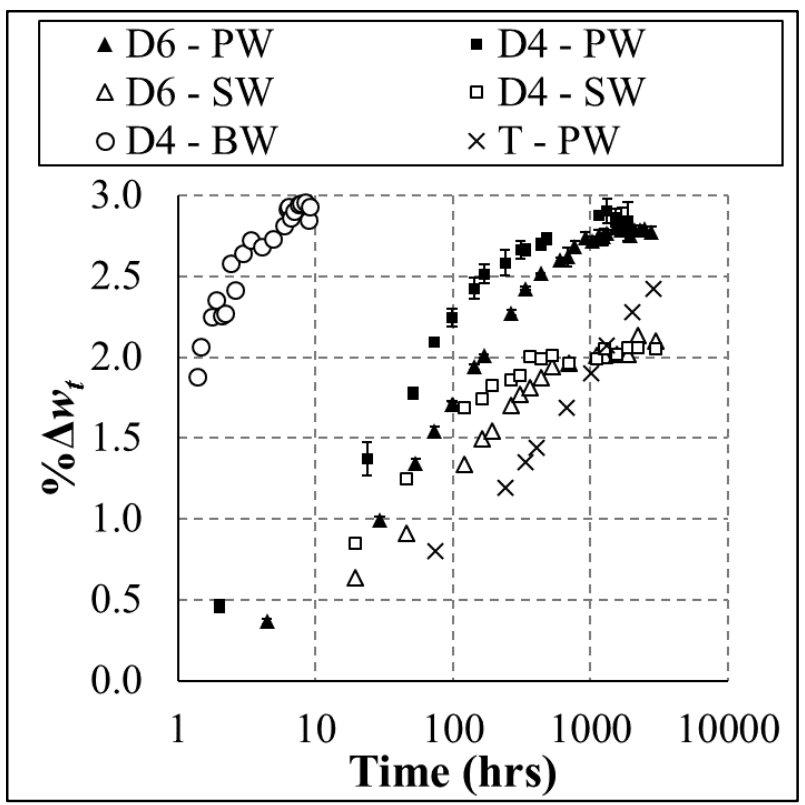

Figure 4. Measurements of the time histories of average water absorption for different compression and tension specimens.

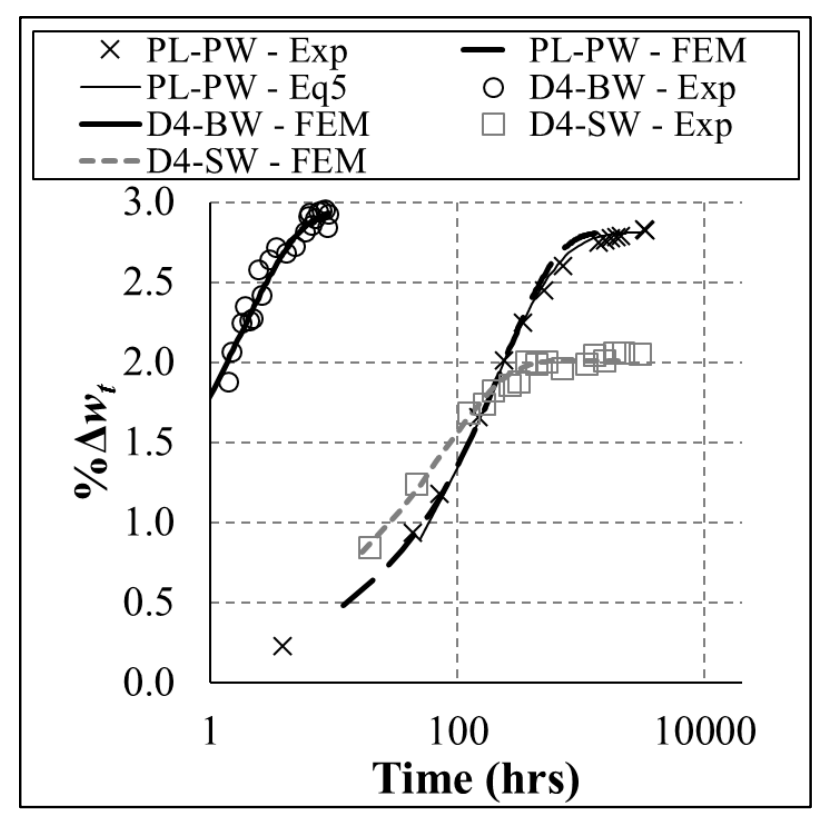

Figure 5. Measurements and predictions of the time histories of average water content. 

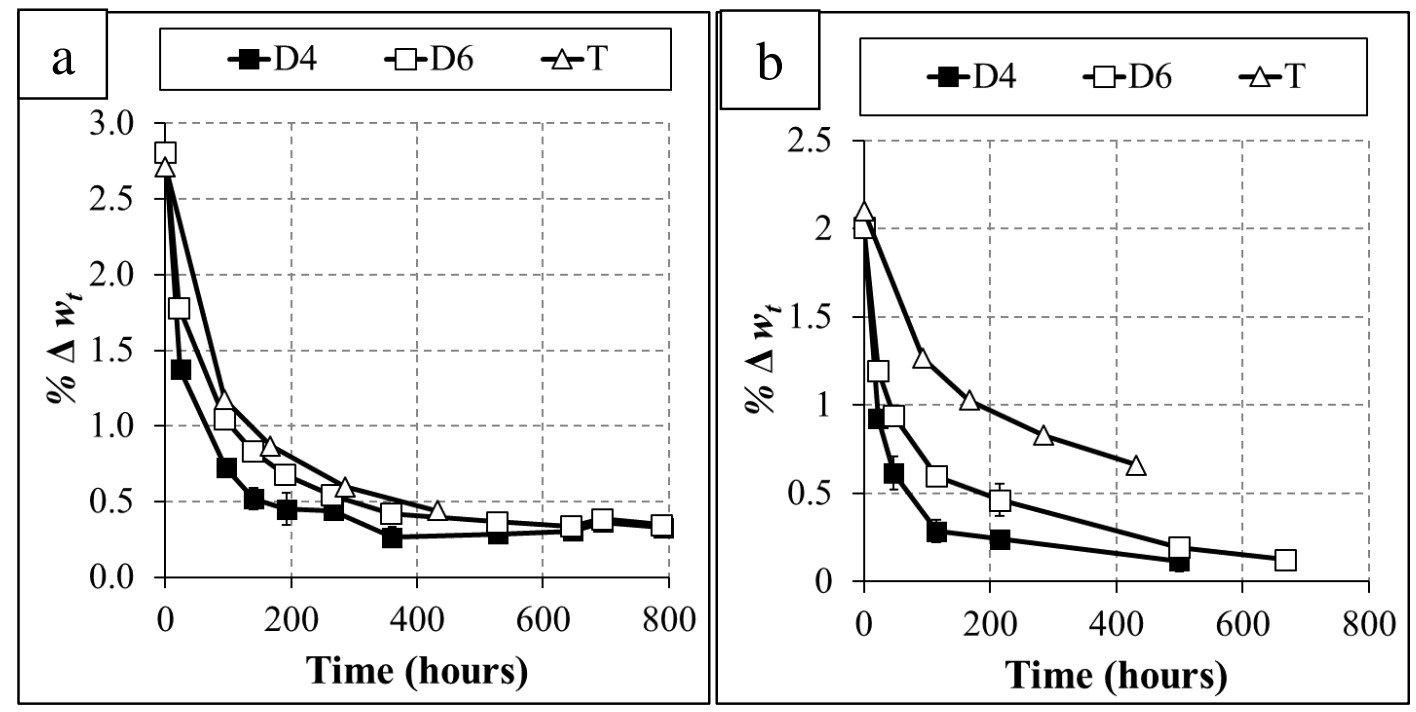

Figure 6. Re-drying of specimens after saturation in (a) pure water and (b) salt water.
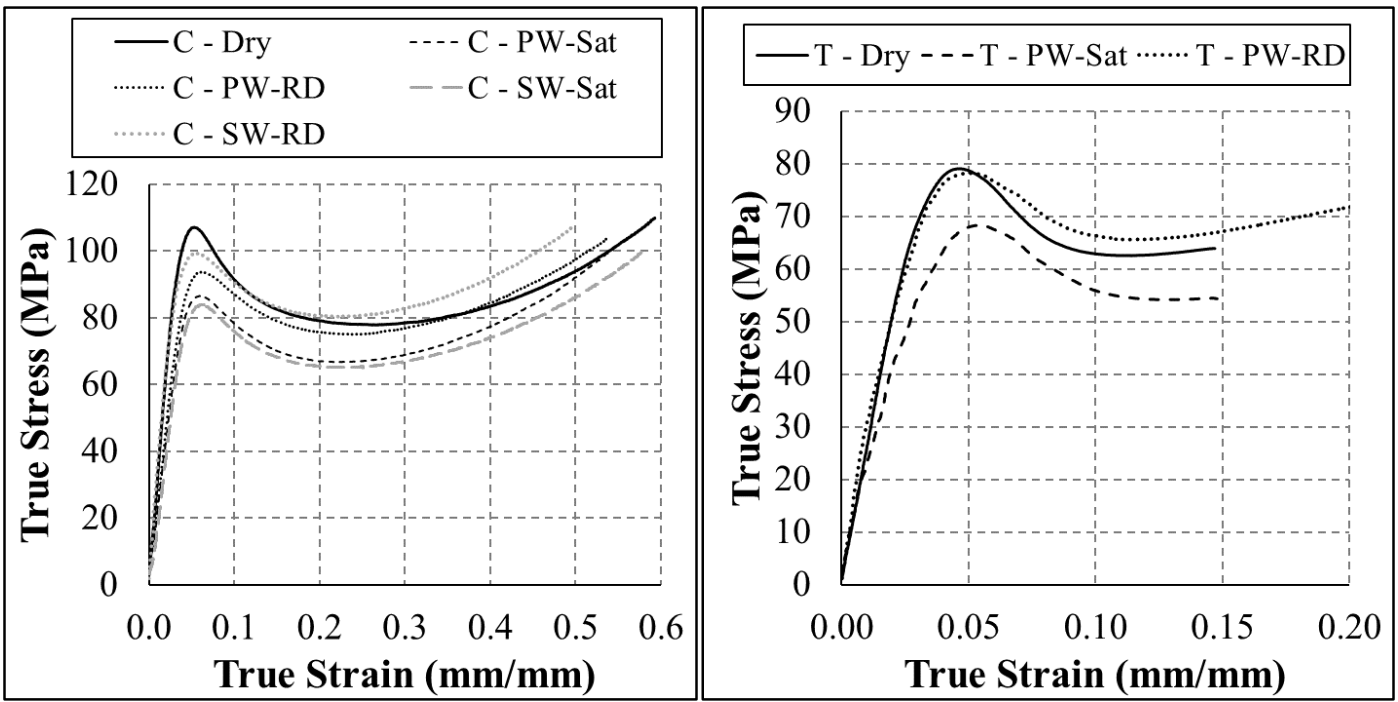

Figure 7. Measured quasi-static strain-stress curves at $\mathbf{1 0}^{\mathbf{- 3}} \mathbf{s}^{\mathbf{- 1}}$.
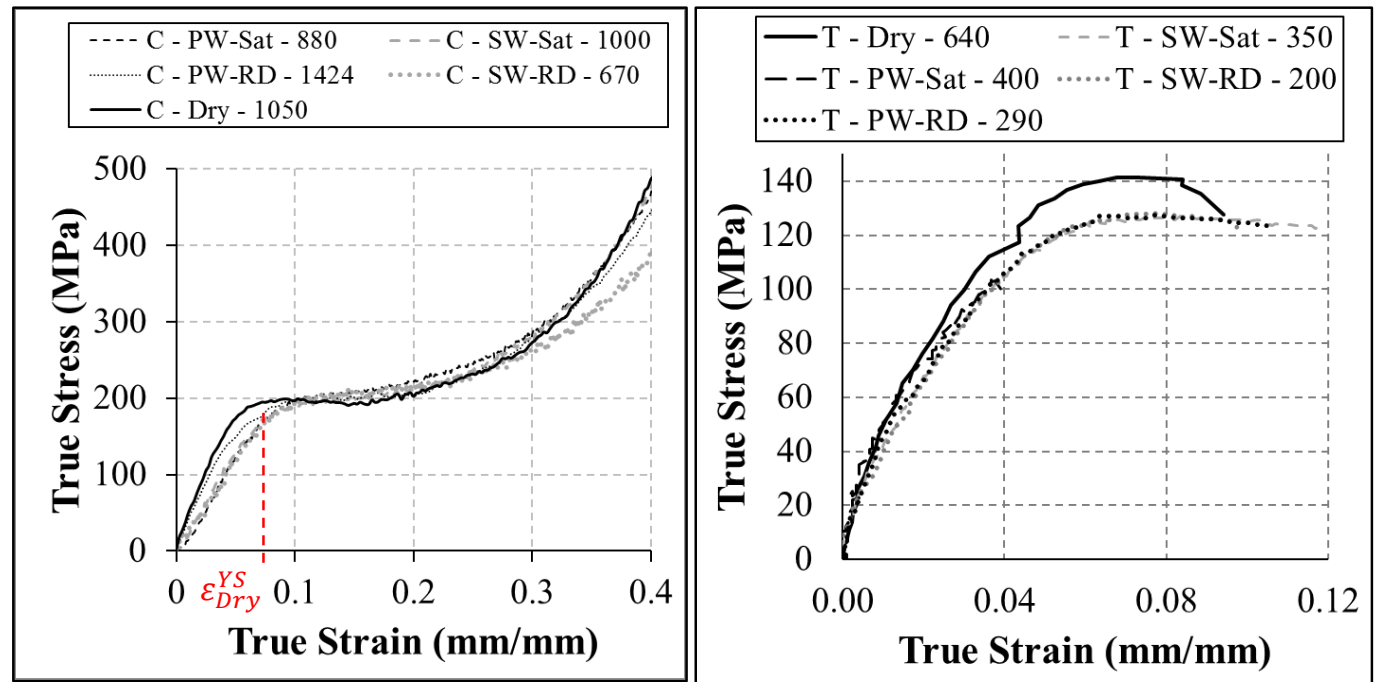

Figure 8. Measured strain-stress curves at high strain rates; the average strain rate (in $\mathbf{s}^{\mathbf{- 1}}$ ) following force equilibrium is indicated by the numbers in the labels. 


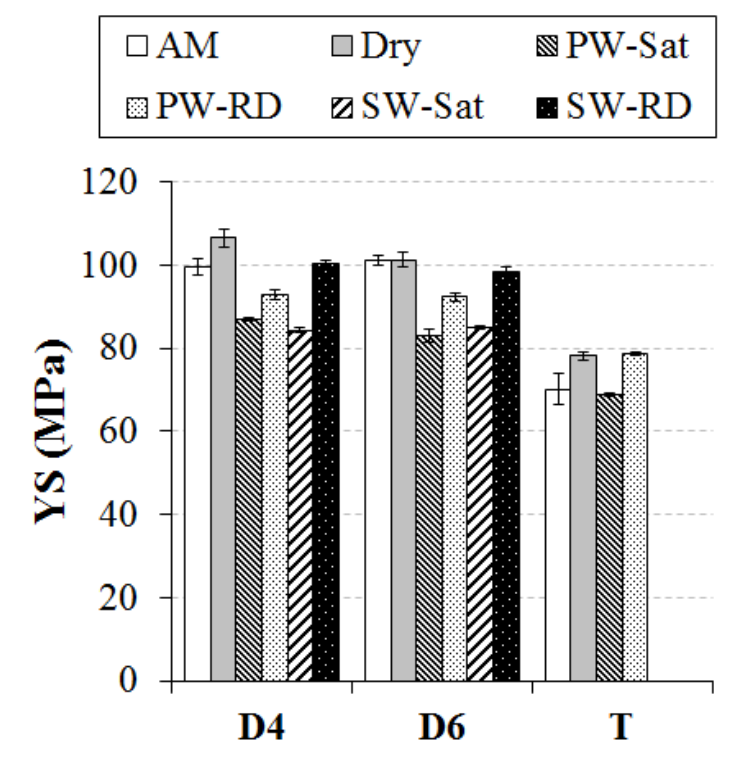

Figure 9. Yield stress at a strain rate of $\mathbf{1 0}^{-\mathbf{3}} \mathrm{s}^{-1}$.

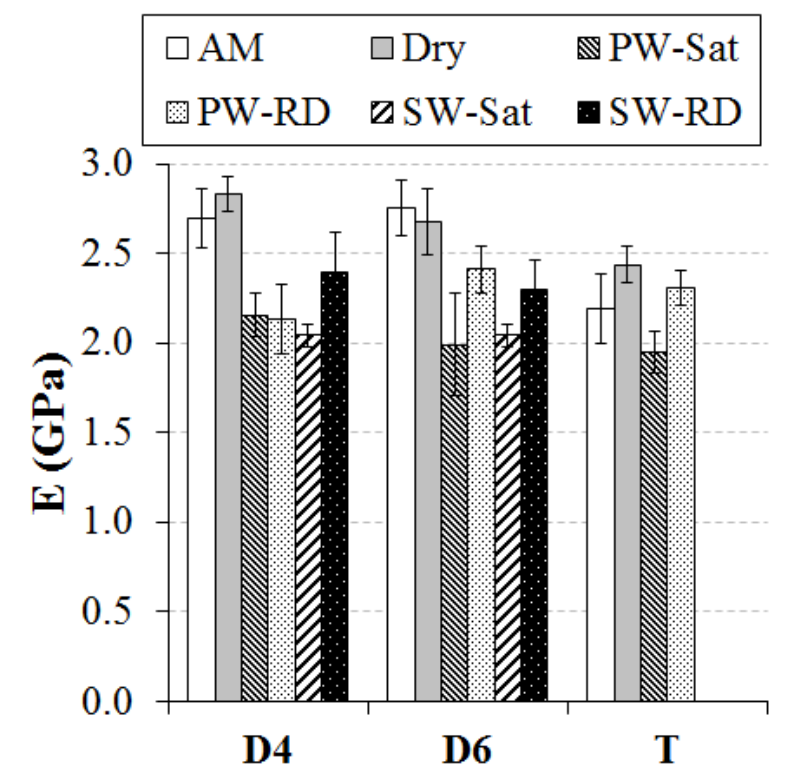

Figure 10. Apparent modulus at a strain rate of $\mathbf{1 0}^{-3} \mathrm{~s}^{-1}$. 


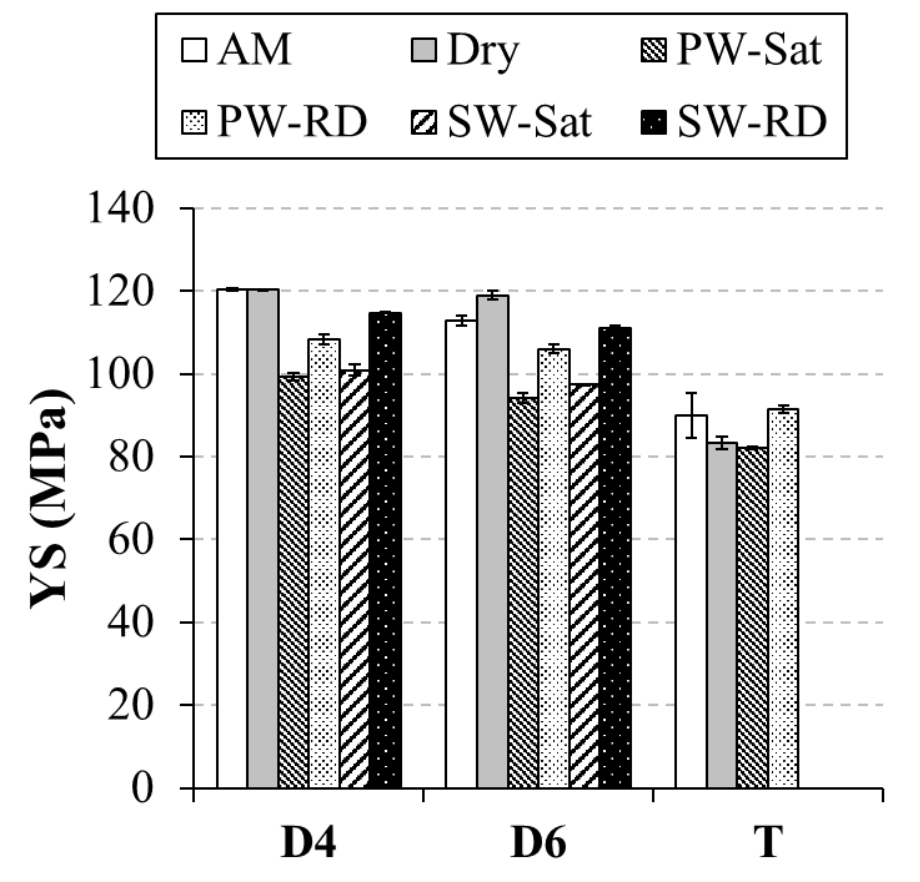

Figure 11. Yield stress at a strain rate of $0.1 \mathrm{~s}^{-1}$.

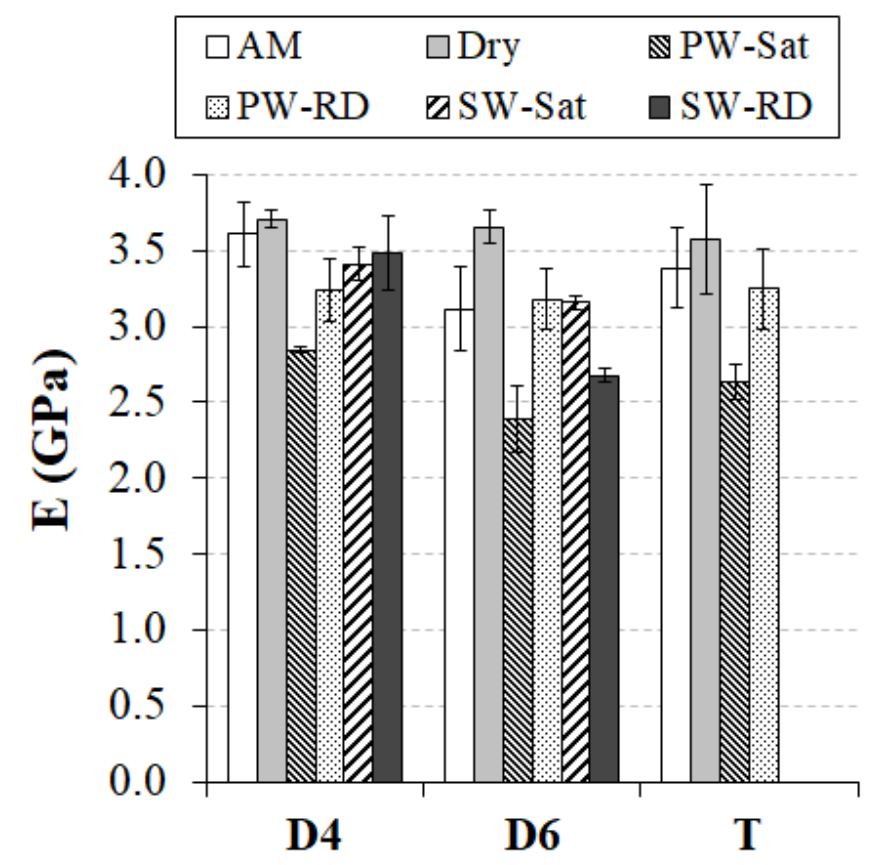

Figure 12. Apparent modulus at a strain rate of $0.1 \mathrm{~s}^{-1}$. 


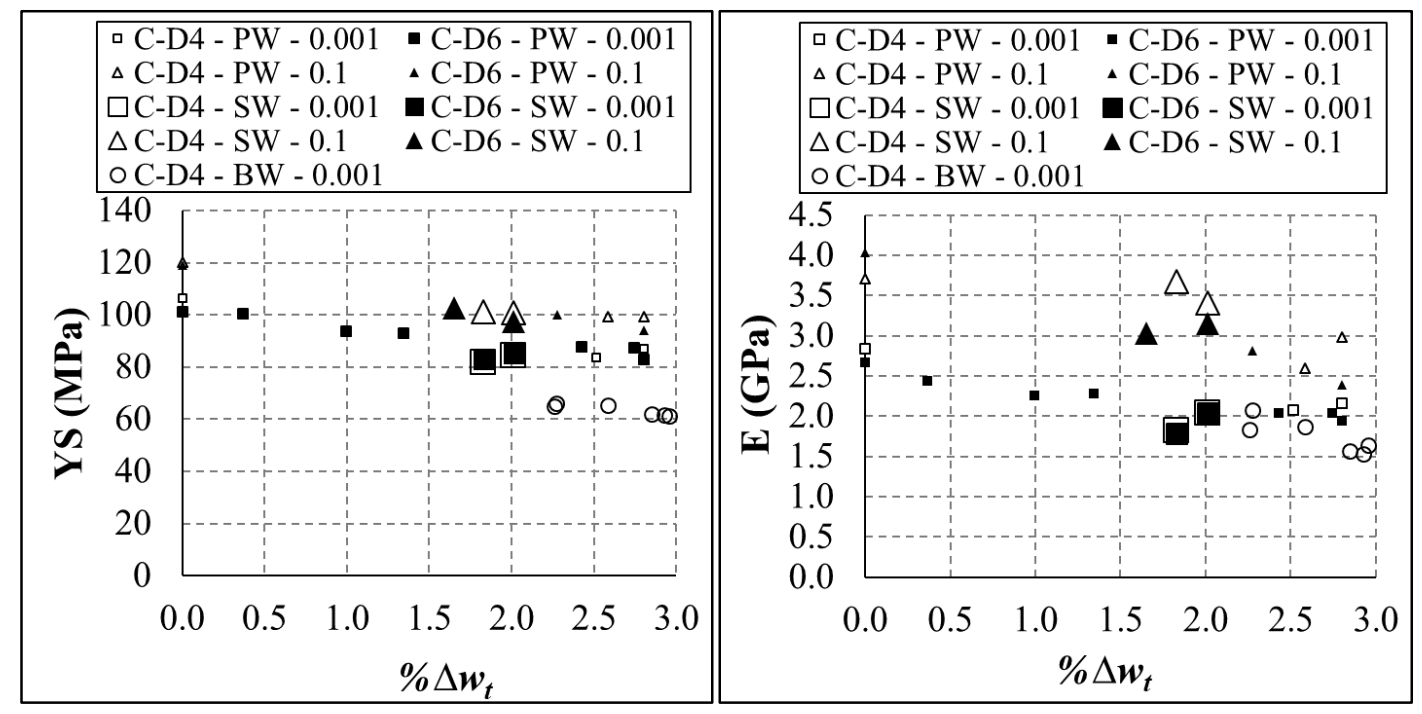

Figure 13. Measured strength and stiffness at different water contents and in different conditioning media.

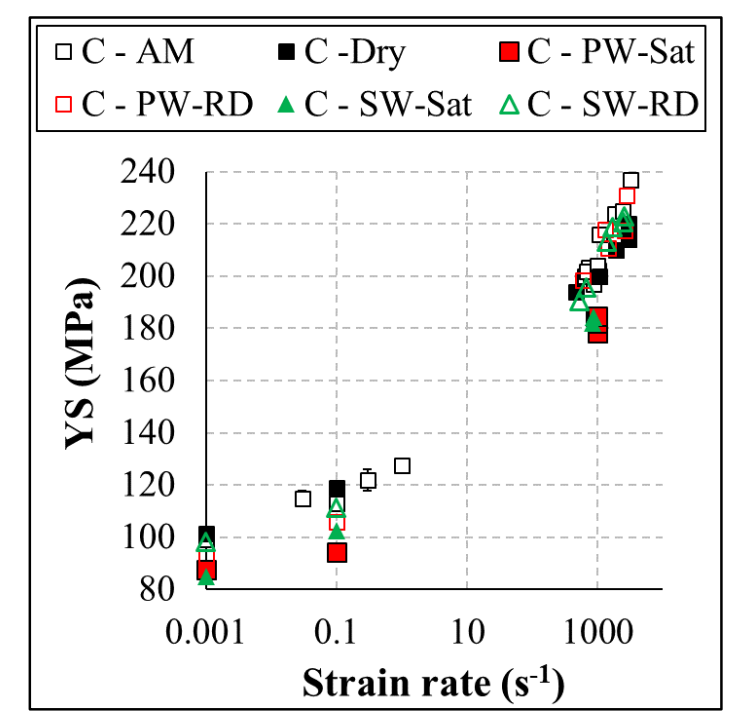

Figure 14. Sensitivity of the compressive strength to the applied strain rate.

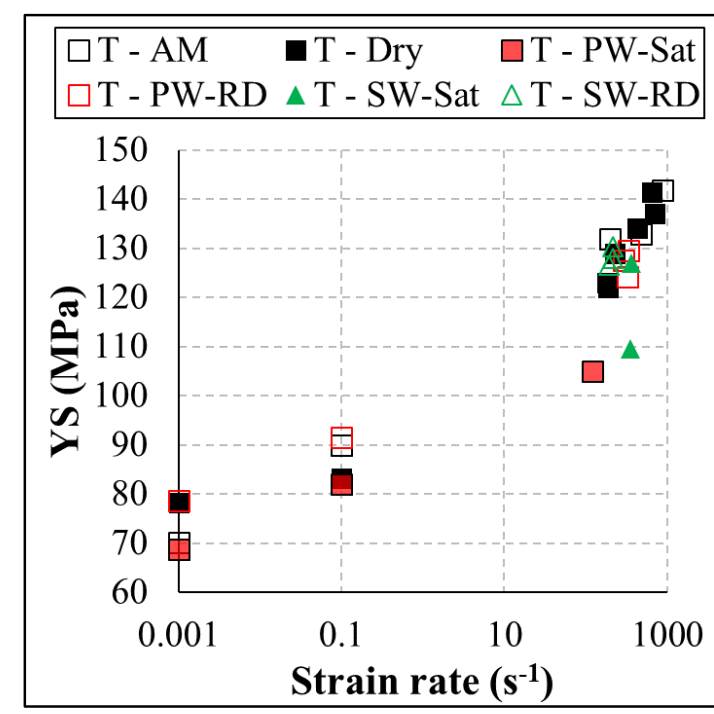

Figure 15. Sensitivity of the tensile strength to the applied strain rate. 


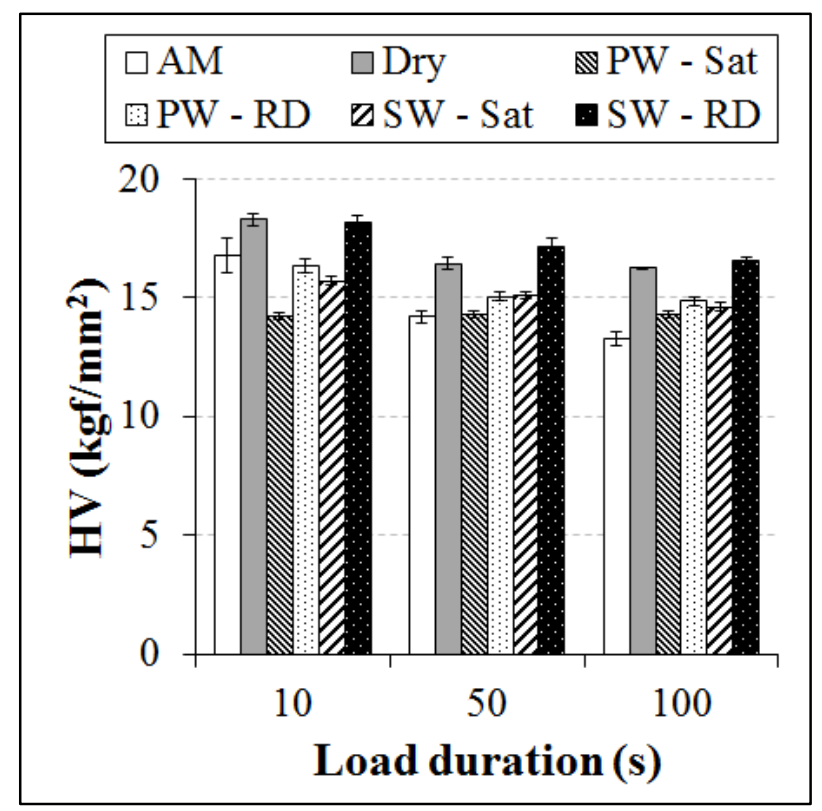

Figure 16. Effects of conditioning and load dwelling duration on the measured Vickers microhardness. 